\title{
Overall Energy Conversion Efficiency of a Thermocatalytic Multi-Step Process to Convert Triglycerides into Fungible Transportation Fuels
}

T.L. Turner ${ }^{1}$ and W.L. Roberts ${ }^{2}$

\author{
${ }^{1}$ Permafuels, Inc. \\ PO Box 1331 \\ Carrboro NC 27510 (USA) \\ Phone:+011919280 7663, e-mail: tim_turner@permafuels.com \\ ${ }^{2}$ Clean Combustion Research Center \\ King Abdullah University of Science and Technology \\ 4220 Al Kindi (West), Thuwal, 23955-6900, Saudi Arabia \\ Phone: 966 (0) 2 808-4909, e-mail: william.roberts@kaust.edu.sa
}

\begin{abstract}
A new fuel process to convert fats and oils to hydrocarbon fuels has been under development since 2006 at North Carolina State University. The process consists of three main reactions steps, with the provision for optional burning of glycerol produced in step one to provide heat inputs for all three steps.
\end{abstract}

This work describes a study involving modeling, analysis, and design optimization to predict the energy conversion efficiency of the overall process. The study predicts an overall efficiency of $89.6 \%$.

\section{Key words}

biofuel, biojet, thermocatalytic, energy conversion efficiency

\section{Introduction}

A new fuel process to convert fats and oils to hydrocarbon fuels has been under development by a multidisciplinary group at North Carolina State University since 2006. The process consists of three main reaction steps [1], [2]:

1. Thermal hydrolysis of triglycerides to form free fatty acids (FFA) and glicerol (GL),

2. Thermocatalytic deoxygenation of FFA to form straight-chain alkanes (n-alkanes), and

3. Thermocatalytic reforming of n-alkanes to produce a mixture of compounds to meet the specifications for jet fuel, diesel fuel, or gasoline (petrol).

In addition, glycerol produced in step 1 may be cleanly combusted to provide heat inputs to all three of the above reaction steps [3]-[5].

Experimental studies by the NC State team and others have investigated the reaction steps as well as the underlying catalyst properties [6]-[35].
A parallel effort, presented here, has focused on modeling, analysis, and optimization of designs for the continuous process, to determine the optimal energy conversion efficiency [36]. A conversion efficiency of $90 \%$ or better is considered to be the long-term goal. Since the biofuel product is essentially energy in liquid form, the energy conversion efficiency has a direct bearing on the economics and the sustainability of the process.

The energy conversion efficiency is defined as

$$
E C E=\frac{\text { combustion energy of product }- \text { energy input }}{\text { combustion energy of feedstock }}
$$

For a three-step process, the overall efficiency is the product of the conversion efficiencies of each step:

$$
\text { Goal }=E C E_{\text {total }}=E C E_{1} E C E_{2} E C E_{3}=0.90
$$

In order to achieve an overall conversion efficiency of $90 \%$, the efficiency of each step needs to be substantially higher, on the order of $97 \%$ :

$$
E C E_{i}=\sqrt[3]{0.90}=0.965
$$

The approach taken is to model each reaction step using the ASPEN simulation package. The output of the simulation is imported into a spreadsheet. Additional calculations are added to keep track of the energy content of all reactants, products, and gases; energy losses due to process inefficiencies; and material and energy balances. The layout of a typical spreadsheet is seen in Table 1. 
Table 1. Schematic of spreadsheet analysis for energy conversion efficiency calculation.

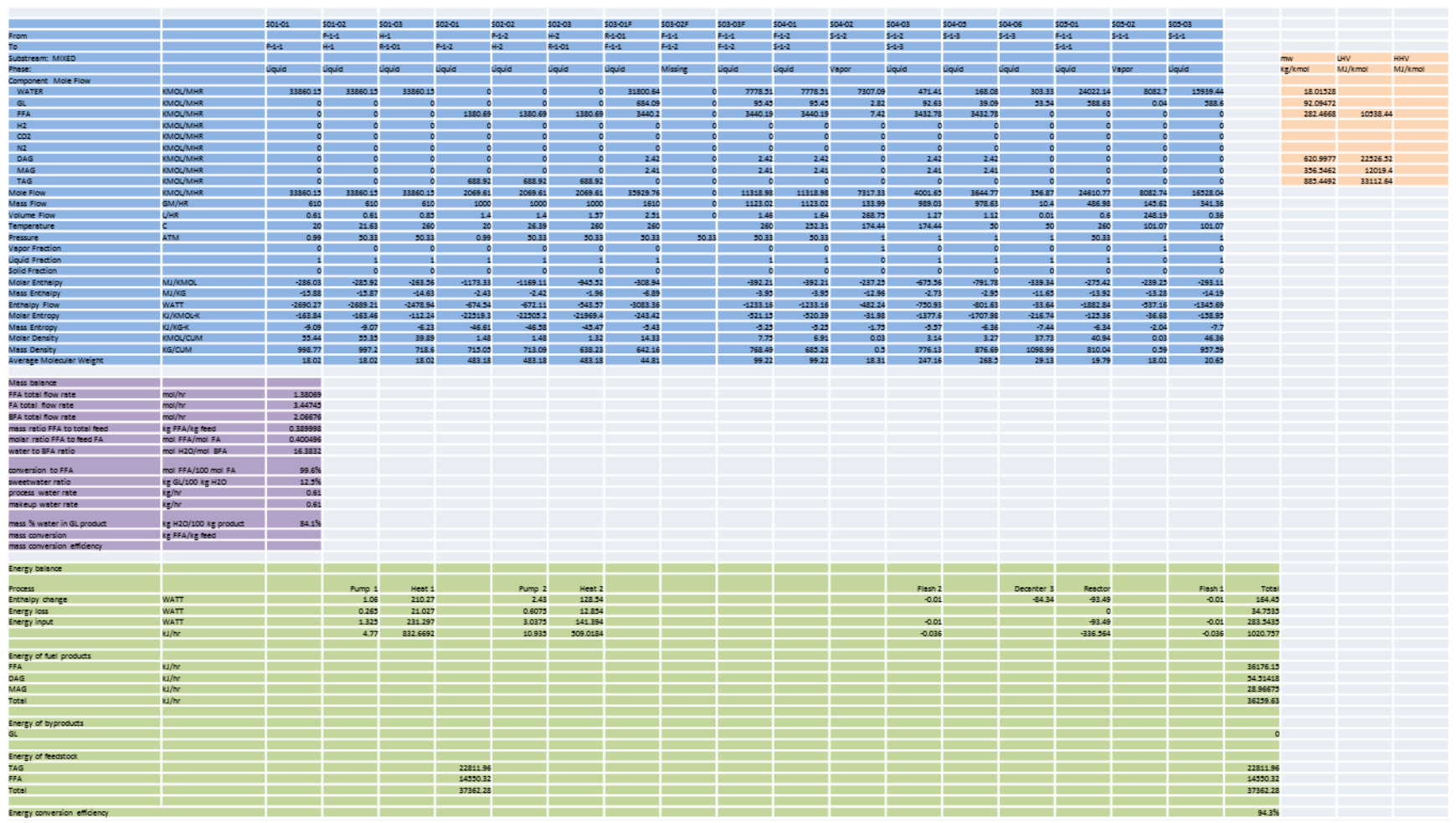

The blue field is the output of the Aspen simulation. The columns represent the process streams, and the rows contain the properties of each stream. The first few rows provide the molar flow rates of each of the component species present. The salmon-colored field at the right keeps track of the energy of combustion of each component species. The purple field contains the mass balance calculations, and the green field holds the energy balance calculation. At the lower right corner of the green field, the energy conversion efficiency is computed.

Our approach has been to model each reaction step as a baseline process, then to model various optimizations, comparing the conversion efficiency of each optimization to the baseline. As it turns out, the challenge for all three steps has been to optimize ancillary operations such as separation processes, rather than the desired reactions themselves.

\section{Step One: Hydrolysis of Triglycerides}

Process step 1 converts triglycerides to free fatty acids by thermal hydrolysis. The reaction produces a byproduct of glycerol, which is leaves the reactor mixed with excess water, in a mixture known as sweetwater. The baseline process has an energy conversion efficiency of around $91 \%$, depending on the feedstock. This can be optimized to around 92 to $95 \%$, depending on the feedstock, without attempting to recover the sweetwater. However, this approach throws away roughly the same mass of water as the feedstock, and discards the glycerol byproduct as well. If conventional distillation is used, the energy conversion efficiency is about the same as the previous, optimized case, but the water requirement is reduced to slightly more than stoichiometric, and high-purity glycerol is available as a fuel or saleable commodity. The best results were obtained by membrane separation. Our design calls for a reverse osmosis (liquid-vapor) process to eliminate about $80 \%$ of the water from the sweetwater, followed by a pervaporation step, resulting in very high purity of the water and glycerol streams. With suitable heat and material recovery, the process efficiency of step 1 with membrane separation is $96 \%$, or $98.7 \%$ counting the combustion energy of the recovered glycerol. This is the recommended approach for step 1 . The process diagram is shown in Figure 1.

\section{Step Two: Deoxygenation of Free Fatty Acids}

Process step 2 removes one carbon atom and the two oxygen atoms from each free fatty acid molecule, to form a long-chain alkane. There are two competing reactions. The desired reaction is decarboxylation:

$$
\mathrm{RCOOH}+\stackrel{\mathrm{cat}, \mathrm{H}_{2}}{\longrightarrow} \mathrm{RH}+\mathrm{CO}_{2}
$$

There is a competing reaction called decarbonylation, which produces carbon monoxide as a byproduct:

$$
\mathrm{RCOOH}+\mathrm{H}_{2} \stackrel{\mathrm{cat} \mathrm{H}_{2}}{\longrightarrow} \mathrm{RH}+\mathrm{CO}+\mathrm{H}_{2} \mathrm{O}
$$

In addition to producing unwanted carbon monoxide, the decarbonylation reaction shortens the life of the catalyst. The decarbonylation reaction can be minimized, but not eliminated, by limiting the amount of hydrogen gas. 


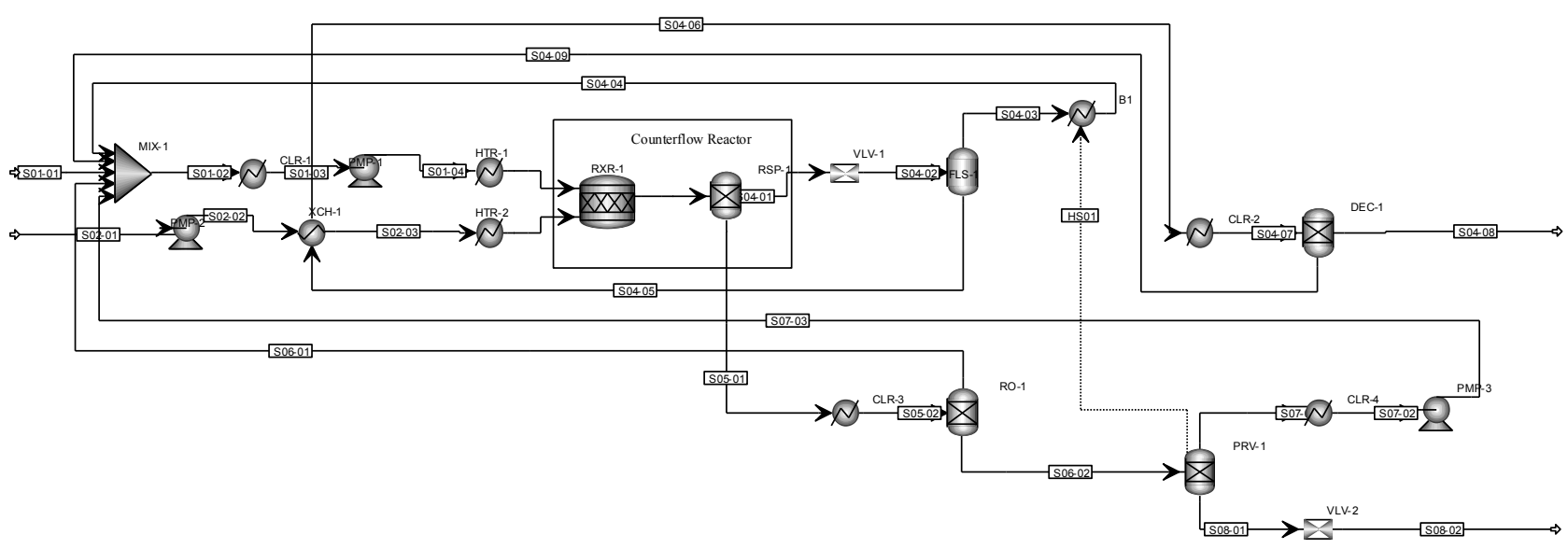

Figure 1. Process step 1 with membrane separation of sweetwater, heat and material recovery. The energy conversion efficiency is $\mathbf{9 8 . 7 \%}$ counting the energy value of the purified glycerol byproduct.

The challenge for step 2 is to eliminate the carbon monoxide, recover the carbon dioxide, and re-use the excess hydrogen as well as the helium carrier gas. Our solution is to recover the carbon dioxide by compressing the gas mixture further, then cooling the mixture until the carbon dioxide condenses out. The remaining carbon monoxide is then catalytically converted to biomethanol by the reaction

$$
\mathrm{CO}+2 \mathrm{H}_{2} \stackrel{\mathrm{CuZnOAl}_{2}}{\longrightarrow} \mathrm{CH}_{3} \mathrm{OH}
$$

This is a standard industrial process for synthesizing methanol. The remaining gases are then hydrogen and helium, which can be returned to the process for re-use. With suitable heat and material recovery, the overall energy conversion efficiency for step 2 is $95.7 \%$. The recommended optimization for step 2 is shown in Figure 2.

\section{Step Three: Reforming of Alkanes}

In process step 3, the straight-chain alkanes are converted to a mix of compounds that is required in order to meet all the standards for the desired fuel. The alkanes are first isomerized and split in a reaction known as hydrocracking. The splitting occurs in such a way that as many short chains are created as there are longer chains. As a result, not all of the resulting molecules are suitable for jet or diesel fuel. Therefore, the strategy is to make as much jet fuel as possible using the longer chains, and to make gasoline from the shorter chains.

The cracked and isomerized molecules are divided into four fractions. The lightest of these are gaseous hydrocarbons. The next group is suitable for gasoline only. The third fraction can be used for either gasoline or jet fuel, and the fourth fraction is suitable for jet fuel only.

We take the third fraction and run a second reaction on it, which creates cyclic and aromatic compounds. The resulting compounds are then divided for use in the gasoline and jet fuel products. The final product streams are 1) gaseous hydrocarbons (fraction 1 above), 2) gasoline made from fraction 2 mixed with cyclic and aromatic compounds made from fraction 3 , and 3) jet fuel made from cyclic and aromatic compounds made from fraction 3, mixed with fraction 4 above.

In order to get clean splits between the fractions, the fractionation column requires a great deal of energy. The column is modeled as a series of three separate columns. The energy requirement decreases in each successive column. The heat duty can be reduced by the use of heat pumps to transfer energy from the cooler distillation unit at the top of the column to the hotter reboiler at the bottom. Because of the high temperatures involved, special refrigerants must be used.

The heat pump for the first column operates between $205^{\circ} \mathrm{C}$ and $359^{\circ} \mathrm{C}$. We investigated a gas-phase heat pump using carbon dioxide as the refrigerant, vs. a

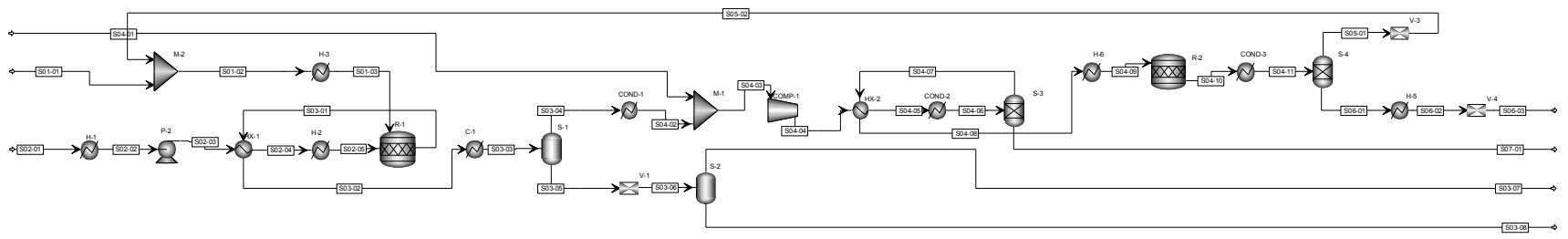

Figure 2. Process step 2 with carbon dioxide recovery, conversion of carbon monoxide to biomethanol, heat and material recovery. Energy conversion efficiency is $\mathbf{9 5 . 7 \%}$. 
conventional heat pump using refrigerant $\mathrm{R}-110$, or hexachloroethane. The second approach is more efficient when real-world devices are considered. The heat pump for the second column uses refrigerant R-140, or 1,1,2chloroethane.

The baseline process has an energy conversion efficiency of only $83.5 \%$. This can be raised to $90.4 \%$ using heat and material recovery. When both heat pumps are added, the efficiency is raised to $94.9 \%$. The process diagram for step 3 is given in Figure 3.

\section{Conclusion}

The overall energy conversion efficiency for the process is the product of the stepwise efficiencies. Thus

$$
E C E=(0.987)(0.957)(0.949)=89.6 \%
$$

This is within a percentage point of the original goal of $90 \%$ efficiency.

\section{Acknowledgement}

This material is based upon work supported by the National Science Foundation EFRI program under Grant EFRI-093772

\section{References}

[1] Turner, T.L., Roberts, W.L., and Stikeleather, L.F., "A Chemical Process for Converting Lipids to Transportation Fuels", Eastern States Section of the Combustion Institute, 2007 Fall Technical Meeting, October 21-24, 2007.

[2] Process for Conversion of Biomass to Fuel. US 7,816,570, Australia 2007347654, European Union 2097496, Germany 602007011667.8, Indonesia P0029151, Mexico 293184, New Zealand 577577, Singapore 152613, South Africa 2009/04021. Other patents pending.

[3] Bohon, M. D., \& Roberts, W. L. (2013). NOx emissions from high swirl turbulent spray flames with highly oxygenated fuels. Proceedings of the Combustion Institute, 34, 1705-1712.

[4] Bohon, M. D., Metzger, B. A., Linak, W. P., King, C. J., \& Roberts, W. L. (2011). Glycerol combustion and emissions. Proceedings of the Combustion Institute, 33, 2717-2724.

[5] Steinmetz, S. A., Herrington, J. S., Winterrowd, C. K., Roberts, W. L., Wendt, J. O. L., \& Linak, W. P. (2013). Crude glycerol combustion: Particulate, acrolein, and other volatile organic emissions. Proceedings of the Combustion
Institute, 34, 2749-2757.

[6] Barnebey, H. L. (1948). Continuous fat splitting plants using the colgate-emery process. Journal of the American Oil Chemists Society, 25(3), 95-99.

[7] Ford, J. P., Immer, J. G., \& Lamb, H. H. (2012). Palladium Catalysts for Fatty Acid Deoxygenation: Influence of the Support and Fatty Acid Chain Length on Decarboxylation Kinetics. Topics in Catalysis, 55(3-4), 175-184.

[8] Holliday, R. L., King, J. W., \& List, G. R. (1997). Hydrolysis of vegetable oils in sub- and supercritical water. Industrial \& Engineering Chemistry Research, 36(3), 932-935.

[9] Immer, J. G., \& Lamb, H. H. (2010). Fed-Batch Catalytic Deoxygenation of Free Fatty Acids. Energy \& Fuels, 24, 5291-5299.

[10] Immer, J. G., Kelly, M. J., \& Lamb, H. H. (2010). Catalytic reaction pathways in liquid-phase deoxygenation of C18 free fatty acids. Applied Catalysis a-General, 375(1), 134-139.

[11] Kelly, M. J., Kim, J., Roberts, G. W., \& Lamb, H. H. (2008). Characterization of Pd/gamma-Al(2)O(3) Catalysts Prepared Using $\mathrm{Pd}(\mathrm{hfac})(2)$ in Liquid $\mathrm{CO}(2)$. Topics in Catalysis, 49(3-4), 178-186.

[12] King, J. W., Holliday, R. L., \& List, G. R. (1999). Hydrolysis of soybean oil in a subcritical water flow reactor. Green Chemistry, 1(6), 261-264.

[13] Kocsisova, T., Juhasz, J., \& Cvengros, J. (2006). Hydrolysis of fatty acid esters in subcritical water. European Journal of Lipid Science and Technology, 108(8), 652-658.

[14] Lamb, H. H., Burkholder, J., Roberts, W. L., Sederoff, H. W., \& Strikeleather, L. F. (2010). EFRI-HyBi: Algal oils to "drop-in" replacements for petroleum transportation fuels. Abstracts of Papers of the American Chemical Society, 240.

[15] Lamb, H. H., Sremaniak, L., \& Whitten, J. L. (2013). Reaction pathways for butanoic acid decarboxylation on the (111) surface of a Pd nanoparticle. Surface Science, 607, 130-137.

[16] Lascaray, L. (1949). MECHANISM OF FAT SPLITTING. Industrial and Engineering Chemistry, 41(4), 786-790.

[17] Lascaray, L. (1952). INDUSTRIAL FAT SPLITTING. Journal of the American Oil Chemists Society, 29(9), 362366.

[18] Lewkowitsch, J. (1921). Chemical Technology and Analysis of Oils, Fats, and Waxes. London: Macmillan and Co.

[19] Maki-Arvela, P., Kubickova, I., Snåre, M., Eranen, K., \& Murzin, D. Y. (2007). Catalytic deoxygenation of fatty acids and their derivatives. Energy \& Fuels, 21(1), 30-41.

[20] Maki-Arvela, P., Snåre, M., Eranen, K., Myllyoja, J., \& Murzin, D. Y. (2008). Continuous decarboxylation of lauric acid over Pd/C catalyst. Fuel, 87(17-18), 3543-3549.

[21] Smit, B., \& Maesen, T. L. M. (2008). Towards a molecular

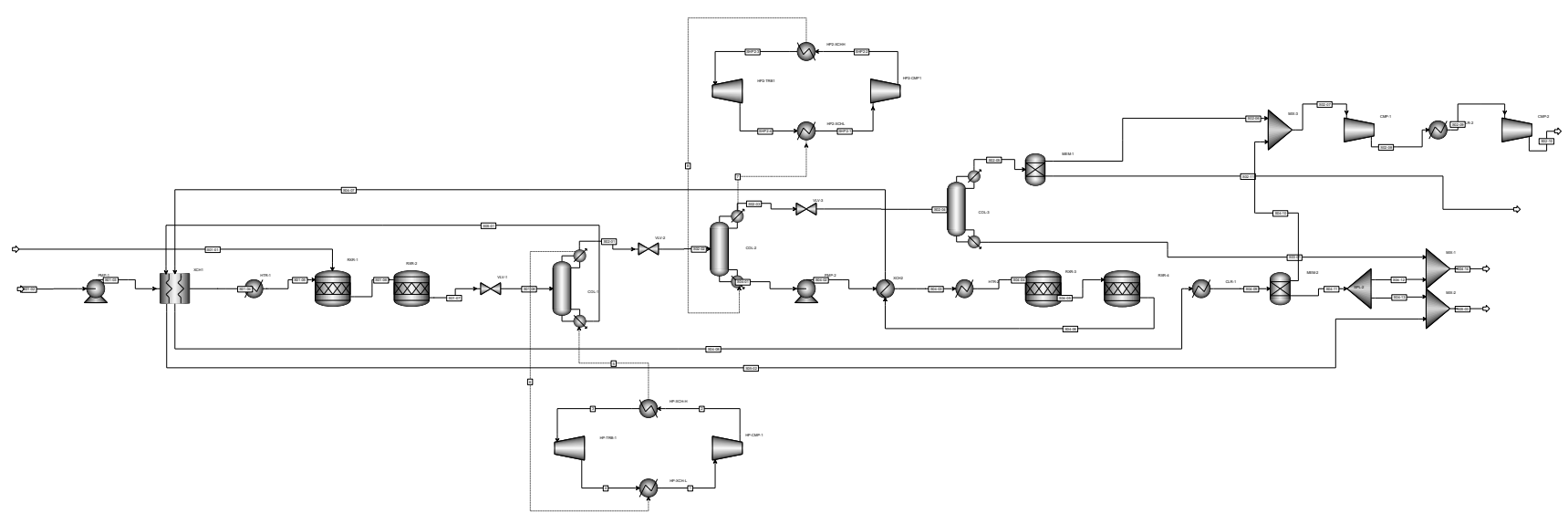

Figure 4. Step 3 process diagram with heat and material recovery, and heat pumps for columns 1 and 2 . The energy https://doi.org/10.24084/repqj12.345 conversion effieancy is $94.9 \%$. RE\&PQJ, Vol.1, No.12, April 2014 
understanding of shape selectivity. [Review]. Nature, 451(7179), 671-678.

[22] Snåre, M., \& Murzin, D. Y. (2006). Reply to "Comment on 'Heterogeneous catalytic deoxygenation of stearic acid for production of biodiesel'". Industrial \& Engineering Chemistry Research, 45(20), 6875-6875.

[23] Snåre, M., Kubickova, I., Maki-Arvela, P., Chichova, D., Eranen, K., \& Murzin, D. Y. (2008). Catalytic deoxygenation of unsaturated renewable feedstocks for production of diesel fuel hydrocarbons. Fuel, 87(6), 933945.

[24] Snåre, M., Kubickova, I., Maki-Arvela, P., Eranen, K., \& Murzin, D. Y. (2006). Heterogeneous catalytic deoxygenation of stearic acid for production of biodiesel. Industrial \& Engineering Chemistry Research, 45(16), 5708-5715.

[25] Snåre, M., Kubickova, I., Maki-Arvela, P., Eranen, K., \& Murzin, D. Y. (2007). Continuous deoxygenation of ethyl stearate: A model reaction for production of diesel fuel hydrocarbons. Catalysis of Organic Reactions (Vol. 115).

[26] Snåre, M., Kubickova, I., Maki-Arvela, P., Eranen, K., Warna, J., \& Murzin, D. Y. (2007). Production of diesel fuel from renewable feeds: Kinetics of ethyl stearate decarboxylation. Chemical Engineering Journal, 134(1-3), 29-34.

[27] Snåre, M., Maki-Arvela, P., Simakova, I. L., Myllyoja, J., \& Murzin, D. Y. (2009). Overview of Catalytic Methods for Production of Next Generation Biodiesel from Natural Oils and Fats. Russian Journal of Physical Chemistry B, 3(7), 1035-1043.
[28] Sturzenegger, A., \& Sturm, H. (1951). Hydrolysis of fats at high temperatures. Industrial and Engineering Chemistry, 43(2), 510-515.

[29] Thapaliya (2012). Study, Optimization and Scale-up of Liquid Phase Deoxygenation of Free Fatty Acids to nalkanes over $5 \% \mathrm{Pd} / \mathrm{C}$ for Biofuel Production. Masters Thesis, North Carolina State University.

[30] Wang, Wei-Cheng (2011). Development of a Small Scale Continuous Hydrolysis Process for Drop In Biofuel Production. NCSU PhD Thesis. http://www.lib.ncsu.edu/resolver/1840.16/8062.

[31] Wang, W. C., Roberts, W. L., \& Stikeleather, L. F. (2012a). Hydrocarbon Fuels From Gas Phase Decarboxylation of Hydrolyzed Free Fatty Acid. Journal of Energy Resources Technology-Transactions of the Asme, 134(3).

[32] Wang, W. C., Thapaliya, N., Campos, A., Stikeleather, L. F., \& Roberts, W. L. (2012b). Hydrocarbon fuels from vegetable oils via hydrolysis and thermo-catalytic decarboxylation. Fuel, 95(1), 622-629.

[33] Wang, W. C., Turner, T. L., Roberts, W. L., \& Stikeleather, L. F. (2012c). Direct injection of superheated steam for continuous hydrolysis reaction. Chemical Engineering and Processing, 59, 52-59.

[34] Wang, W. C., Turner, T. L., Stikeleather, L. F., \& Roberts, W. L. (2012d). Exploration of process parameters for continuous hydrolysis of canola oil, camelina oil and algal oil. Chemical Engineering and Processing, 57-58, 51-58.

[35] Yin, M. C., Natelson, R. H., Campos, A. A., Kolar, P., \& Roberts, W. L. (2013). Aromatization of n-octane over $\mathrm{Pd} / \mathrm{C}$ catalysts. Fuel, 103, 408-413.

[36] Turner, T.L. A Chemical Process to Convert Fats and Oils to Hydrocarbon Fuels. NCSU PhD Thesis, 2013. 